\title{
Remission of diarrhoea due to cryptosporidiosis in an immunodeficient child treated with hyperimmune bovine colostrum
}

\author{
S TZIPORI, D ROBERTON, C CHAPMAN
}

\begin{abstract}
A boy aged 6 months who presented with poor weight gain, diarrhoea, and infection with Pneumocystis carinii was found to have congenital hypogammaglobulinaemia, which did not improve despite monthly treatment with intravenous gammaglobulin. At the age of 3 years and 2 months he developed severe vomiting and diarrhoea due to cryptosporidiosis, which failed to respond to conventional treatment. Infusion of hyperimmune bovine colostrum produced against parasite antigen, given by nasogastric tube, was started after symptoms had persisted for three weeks. His vomiting and diarrhoea resolved within five days of treatment, and oocysts were no longer seen in the stools after eight days. Later, however, he developed a rare complication, and oocysts were found in the common bile duct.

Hyperimmune bovine colostrum may be useful in the treatment of many patients with immunodeficiency disorders.
\end{abstract}

\section{Introduction}

Cryptosporidiosis is a major problem in the management of immunologically compromised patients and may lead to chronic malabsorption and severe weight loss. Infections in immunodeficient patients were reported first in patients with hypogammaglobulinaemia ${ }^{12}$; more recently cryptosporidiosis has become important in patients with the acquired immune deficiency syndrome. ${ }^{3}$ Chemotherapeutic drugs such as spiramycin have generally proved ineffective. ${ }^{4}$ We describe remission of diarrhoea due to cryptosporidiosis after treatment with hyperimmune bovine colostrum in a child with hypogammaglobulinaemia.

\section{Case report}

The patient first presented at the age of 6 months with poor weight gain, diarrhoea of two months' duration, and pneumonia due to Pneumocystis carinii. His serum IgG concentration was $0.52 \mathrm{~g} / \mathrm{l}$ (third percentile for 6 months of age $=1.74 \mathrm{~g} / \mathrm{l}), \mathrm{IgA}$ was absent, and his $\operatorname{IgM}$ concentration was $0.89 \mathrm{~g} / \mathrm{l}$ (third percentile $=0.17 \mathrm{~g} / \mathrm{l}$ ). Lymphocyte responses to mitogens and to allogeneic cells were normal. Two populations of B lymphocytes were present in peripheral blood; $13 \%$ had a mature B cell phenotype ( $\mathrm{SIg}^{*}, \mathrm{Y} 29$ / $55^{+}, \mathrm{Ia}^{*}, \mathrm{FMCl}^{*}$ ), and $7 \%$ had an immature $\mathrm{B}$ cell phenotype (CALLA', $\left.\mathrm{Y} 29 / 55^{+}, \mathrm{Ia}^{+}\right)$. Immunoperoxidase staining of duodenal biopsy specimens showed cells producing IgM but no cells producing IgA or IgG. There was no family history of hypogammaglobulinaemia. His mother had never received any blood products, and she and the patient were both negative for antibodies to human immunodeficiency virus. He received intravenous gammaglobulin $10 \mathrm{ml} / \mathrm{kg}$ monthly after diagnosis, and his immunoglobulin concentrations remained consistent with a diagnosis of hypogammaglobulinaemia with IgM.

\footnotetext{
Departments of Microbiology and Immunology, Royal Children's Hospital, Parkville, Victoria 3052, Australia

S TZIPORI, DVSC, PHD, deputy director of microbiology

D ROBERTON, MD, FRACP, clinical immunologist and senior lecturer in paediatrics

Attwood Institute for Veterinary Research, Westmeadows, Victoria 3047, Australia

C CHAPMAN, BVSC, PHD, senior veterinary scientist

Correspondence to: Dr Tzipori.
}

At the age of 3 years and 2 months he developed persistent vomiting anç watery diarrhoea. He was admitted to hospital and was rehydrated wit intravenous fluid, but diarrhoea and vomiting continued. Cryptosporidiur oocysts were detected repeatedly in his stools over the next three weeks Duodenal biopsy specimens showed endogenous stages of the parasite on th microvillus border of epithelial cells. Three weeks after the onset of diarrhoeal illness he began treatment with hyperimmune colostrum frorfp cows previously immunised with cryptosporidium antigens.

The hyperimmune colostrum was prepared by immunising two pregnant dairy cows 10 weeks before calving either with Percoll purified wholes oocysts ${ }^{5}$ or with sporozoites that were excysted by treatment with trypsiR and bile salts from Percoll purified oocysts. The cows were given $2 \mathrm{~m}$ intramuscular injections of about $10^{5}$ intact or excysted oocysts $/ \mathrm{m}$. $\left(=4 \times 10^{5}\right.$ sporozoites $\left./ \mathrm{ml}\right)$, mixed with an equal volume of Freund's completeo adjuvant. Two weeks later they were reimmunised by intramammary infusion into each quarter with the same antigens mixed with an equars volume of Freund's incomplete adjuvant. The cows were milked ims mediately after parturition, and the colostrum was stored at $-20^{\circ} \mathrm{C}$. Samplest of colostrum from both cows on the second day after parturition were mixed in equal volumes before use. Challenge of specific pathogen free mice with mixture of excysted oocysts and a 1:10 dilution of heated hyperimmune colostrum (at $56^{\circ} \mathrm{C}$ for 30 minutes) showed complete protection from infection, whereas infection occurred at nine days in mice challenged with oocysts and heated non-immune colostrum and at four days in mice challenged with oocysts alone.

Microbiological assays of the colostrum showed only 25 colony forming units of bacteria of bovine origin (Streptococcus spp and lactose fermentersp per $\mathrm{ml}$ of colostrum. The patient received $200 \mathrm{ml}$ of untreated hyperimmune colostrum mixed with $800 \mathrm{ml}$ Digestalac given daily at a rate of $45 \mathrm{ml} / \mathrm{h} \mathrm{b}$ nasogastric tube for 12 days. He then received $50 \mathrm{ml}$ of colostrum orally fơ four days. Vomiting stopped three days after treatment was begun, and the watery diarrhoea resolved after five days. Sequential examination of faece? showed a decrease in the numbers of oocysts after two days of treatment? oocysts had disappeared completely within eight days and were not detecte again. When he was discharged, 20 days after treatment was begun, he wa⿱ well, had a good appetite, and was passing one to three semiformed stool daily and his weight had returned to normal. During the four months afte treatment he had no further diarrhoea and his stools were free o\$ cryptosporidium oocysts. Recent investigations after a transient rise iw concentration of hepatic enzymes, however, showed dilatation of the bile duct with oocysts in fluid aspirated directly from the common bile duct.

\section{Discussion}

In two children with congenital hypogammaglobulinaemia an cryptosporidiosis described previously diarrhoea persisted despite exhaustive treatment with various chemotherapeutic drugs. One child had chronic diarrhoea that lasted for four years and remainedo unresolved, ${ }^{2}$ and a second child, who also had hypogammas globulinaemia with raised IgM concentrations, died after protractes. diarrhoea lasting six years. ${ }^{2}$

After our patient was treated with hyperimmune bovine colo strum faeces were found to be free of oocysts and diarrhoea stopped The major secretory immunoglobulin in the cow is IgGl, whick fulfils the same role in ruminants as IgA does in monogastric specie by being resistant to low $\mathrm{pH}$ and luminal proteolysis. ${ }^{6}$ Colostrum i therefore more likely to be effective when administered orally than is purified bovine serum IgG. Experiments in mice showed \& protective effect of heated hyperimmune colostrum on challeng with cryptosporidium oocysts, suggesting that neutralising activity was present. The colostrum was effective in our patient when giver? without the use of histamine antagonists or antacids.

Two issues warrant further investigation: the usefulness of thi treatment in patients with $T$ lymphocyte dysfunction, and whethe colostrum from non-immunised cows is effective when it is used it 
larger volumes. As cryptosporidiosis is very common in bovine species ordinary colostrum from some cows may be effective. Hyperimmune bovine colostrum is safer than most drugs, which is a consideration when treating debilitated patients, and, should microbial contamination of colostrum pose a problem in immunodeficient individuals, it could be gamma irradiated without affecting the immunoglobulin concentration. Hyperimmune bovine colostrum appears to be a useful adjunct in the treatment of diarrhoea due to infection with cryptosporidium in patients with immunodeficiency disorders, particularly those in whom treatment with antibiotics has failed. In this patient, however, the rare complication of ascending biliary tract infection was not prevented.

\section{References}

1 Lasser KH, Lewin KJ, Ryning FW. Cryptosporidial enteritis in a patient with congenital hypogammaglobulinaemia. Hum Pathol 1979;10:234-40.

2 Sloper KS, Dourmashkin RR, Bird RB, Slavin G, Webster ADB. Chronic malabsorption due to cryptosporidiosis in a child with immunoglobulin deficiency. Gut 1982;23:80-2.

3 Anonymous. Treatment of cryptosporidiosis in patients with acquired immunodeficiency syndrome (AIDS). MMWR 1984;33:117-9.

4 Casemore DP, Sands RL, Curry A. Cryptosporidium species a "new" human pathogen. $7 \mathrm{Clin}$ Pathol 1985;38:1321-36.

5 Waldman E, Tzipori S, Forsyth JRL. Separation of Cryptosporidium oocysts from faeces using Percoll discontinuous density gradient. F Clin Microbiol 1986;23:199-200.

6 Saif L. Passive immunity to coronavirus and rotavirus infections in swine and cattle: enhancement by maternal vaccination. In: Tzipori S, ed. Infectious diarthoea in the young. Excerpta Medica (Int. Conf. 674) 456-67.

(Accepted 5 September 1986)

\section{SHORT REPORTS}

\section{Paradoxical gas embolism in a scuba diver with an atrial septal defect}

Paradoxical gas embolism has been described during subatmospheric decompresssion in aviators with intracardiac shunts. ${ }^{.}$We report on a diver with an undiagnosed atrial septal defect who had the clinical features of air embolism without apparent cause.

\section{Case report}

A scuba diver developed symptoms after a dive to $38 \mathrm{~m}$ for 15 minutes. He had made 100 previous dives, but none had been as deep. He had never performed a dive requiring decompression stops and had not dived during the preceding two weeks. He ascended at an appropriate rate $(15 \mathrm{~m} / \mathrm{min})$ but failed to make decompression stops. Two minutes after surfacing he noticed abdominal pain, unilateral paraesthesia, and dizziness. A few seconds later he became unconscious. All symptoms resolved over the next 30 minutes. His two diving companions had no adverse effects.

Six hours later he noticed progressive weakness and paraesthesia in both legs but did not seek treatment until the next day. At that time he had mixed motor and sensory paraplegia and his speech was slurred. A chest $x$ ray film showed no evidence of pulmonary barotrauma. Recompression was performed immediately Fasciculation and paraesthesia in his legs resolved within five minutes. After recompression mild paraparesis remained, which improved over the following year.

He was subsequently found to have fixed splitting of the second heart sound and a pulmonary systolic murmur. Cardiac catheterisation confirmed the presence of a secundum atrial septal defect. The ratio of pulmonary to systemic flow was 3:1. Valsalva's manoeuvre, oxygen breathing, and straight leg raising all produced bidirectional shunting, confirmed by dye dilution. There was no right to left component to the shunt while he was supine and breathing air. The atrial septal defect was corrected surgically, and he was advised not to dive.

\section{Comment}

Pulmonary barotrauma and decompression sickness may result from the ascent after a dive. ${ }^{2}$ Decompression sickness results from the release of bubbles of nitrogen from solution as pressure is reduced. Unless large and rapid changes in pressure occur the symptoms and signs of decompression sickness develop over several hours. The dive performed was only just long enough to require decompression stops according to the air diving decompression table of the Royal Navy Physiological Laboratory and British SubAqua Club. Failure to perform stops placed the divers at risk of developing decompression sickness. The paraplegia that developed six hours after the dive was typical of decompression sickness, though the early symptoms were not.

Syncope immediately after surfacing as well as unilateral and unimodal neurological symptoms are characteristic of arterial gas embolism, not decompression sickness. ${ }^{2}$ Arterial gas embolism is usually the result of air embolism due to pulmonary barotrauma, but no cause for this was found. After all dives nitrogen bubbles are formed in the venous system ${ }^{3}$ but are trapped in the pulmonary capillaries without producing symptoms. In this patient the embolus was probably not air from pulmonary barotrauma but paradoxical embolism of venous nitrogen bubbles.

Although the patient had only a left to right shunt at rest, several manoeuvres caused bidirectional shunting. Immersion and exposure of divers to cold increase cardiac filling pressure, as does straight leg raising, and might reverse the shunt. ${ }^{45}$ During scuba diving the partial pressure of oxygen is increased. This can have considerable haemodynamic effects. ${ }^{5} \mathrm{~A}$ raised partial pressure of oxygen caused bidirectional shunting in the patient, as did Valsalva's manoeuvre, which is used by divers to equalise ear pressures. Thus conditions during diving favoured paradoxical embolisation of venous bubbles. Because this dive was deeper than all others the patient had performed it produced the greatest blood nitrogen load and hence the greatest number of bubbles during decompression. It was therefore the one most likely to produce symptoms.

This case emphasises the importance of advising people with intracardiac shunts not to dive.

1 Fryer DI. Subatmospheric decompression sickness in man. Slough. Technivision, 1969-209-10.

2 Douglas JDM. Medical problems of sport diving. Br Med f 1985;291:1224-6.

3 Daniels S, Davies JM, Paton WDM, Smith EB. Recent experiments using ultrasonic imaging to monitor bubble formation in divers. In: Bachrach AJ, Matzen MM, eds. Underwater physiology VIII. Betheseda, Maryland: Undersea Medical Society, 1984:249-57.

4 Arborelius M, Balldin UI, Lilja B, Lundgren CEG. Haemodynamic changes in man during immersion with the head above water. Aerospace Medicine 1972;43:592-8.

5 Wilmshurst PT, Nuri M, Crowther A, Betts JC, Webb-Peploe MM. Recurrent pulmonary edema in scuba divers; prodrome of hypertension: a new syndrome. In: Bachrach AJ, Matzen MM, eds. Underwater physiology VIII. Bethesda, Maryland: Undersea Medical Society, 1984:327-39.

(Accepted 13 August 1986

St Thomas's Hospital, London SE1 7EH

P T WILMSHURST, MB, MRCP, senior registrar in cardiology

B G ELLIS, PHD, MRCP, senior house officer in intensive care

B S JENKINS, MB, FRCP, consultant cardiologist

Correspondence to: Dr Wilmshurst.

\section{Hyperparathyroidism associated with severe hypercalcaemia and myocardial calcification despite minimal bone disease}

Although rare, ${ }^{1}$ hyperparathyroid crisis can be cured. Successful treatment depends on early recognition.

\section{Case report}

A 61 year old woman was admitted as an emergency. She was hypotensive and confused. She had been "slowing up" for two years and over the past three weeks had developed pains in the arms and legs, anorexia, indigestion, urinary frequency, and breathlessness. She had not seen a doctor until the previous day. The results of general examination were unremarkable. She had atrial fibrillation at 110 beats/min with a supine blood pressure of $80 / 40 \mathrm{~mm} \mathrm{Hg}$ (phase V). Her central venous pressure was measured at $12 \mathrm{~cm} \mathrm{H}_{2} \mathrm{O}$. There was no heart murmur. She was tachypnoeic and had bilateral fine basal crackles but no peripheral oedema.

Initial investigations showed a haemoglobin concentration of $129 \mathrm{~g} / \mathrm{l}$ and a white blood cell count of $28.5 \times 10^{9} / 1$ with neutrophilia. Plasma electrolyte concentrations were: sodium $134 \mathrm{mmol}(\mathrm{mEq}) / 1$, potassium $2.5 \mathrm{mmol}(\mathrm{mEq}) / 1$ urea $26.3 \mathrm{mmol} / \mathrm{l}(159 \mathrm{mg} / 100 \mathrm{ml})$, creatinine $211 \mu \mathrm{mol} / \mathrm{l}(2.4 \mathrm{mg} / 100 \mathrm{ml})$, and 